\title{
CONF-9609237--2
}

\section{BIODESULFURIZATION OF DIBENZOTHIOPHENE AND CRUDE OIL USING ELECTRO-SPRAY REACTORS*}

\author{
Eric N. Kaufman, James B. Harkins, Miguel Rodriguez, \\ Costas Tsouris, and Punjai T. Selvaraj
}

Oak Ridge National Laboratory

Chemical Technology Division

P.O. Box 2008

Oak Ridge, Tennessee 37831-6226

To be presented at

Proceedings of the 3rd Annual International Petroleum Environmental Conference

Albuquerque, New Mexico

September 24-27, 1996

\begin{abstract}
"The submitted manuscript has been authored
by a contractor of the U.S. Government

under contract DE-AC05-96OR22464.

Accordingly, the U.S. Government retains a

nonexclusive, royalty-free license to

publish or reproduce the published form

of this contribution, or allow others to

do so, for U.S. Government purposes."
\end{abstract}

MASTER

DISTAIBUTION OF THIS DOCUMENT IS UNLIMITED

*Research sponsored by the Advanced Research and Technology Development Program of the Office of Fossil Energy, U.S. Department of Energy under contract DE-AC05-96OR22464 with Lockheed Martin Energy Research Corp. 


\section{DISCLAIMER}

Portions of this document may be illegible in electronic image products. Images are produced from the best available original document. 


\section{DISCLAIMER}

This report was prepared as an account of work sponsored by an agency of the United States Government. Neither the United States Government nor any agency thereof, nor any of their employees, makes any warranty, express or implied, or assumes any legal liability or responsibility for the accuracy, completeness, or usefulness of any information, apparatus, product, or process disclosed, or represents that its use would not infringe privately owned rights. Reference herein to any specific commercial product, process, or service by trade name, trademark, manufacturer, or otherwise does not necessarily constitute or imply its endorsement, recommendation, or favoring by the United States Government or any agency thereof. The views and opinions of authors expressed herein do not necessarily state or reflect those of the United States Government or any agency thereof. 


\title{
Biodesulfurization of Dibenzothiophene and Crude Oil Using Electro-Spray Reactors
}

\author{
Eric N. Kaufman ${ }^{*}$, James B. Harkins, Miguel Rodriguez, \\ Costas Tsouris, and Punjai T. Selvaraj \\ Chemical Technology Division \\ Oak Ridge National Laboratory ${ }^{\dagger}$ \\ Oak Ridge, Tennessee, USA 37831-6226
}

Biological removal of organic sulfur from petroleum feedstocks offers an attractive alternative to conventional thermochemical treatment due to the mild operating conditions afforded by the biocatalyst. In order for biodesulfurization to realize commercial success, reactors must be designed which allow for sufficient liquid / liquid and gas / liquid mass transfer while simultaneously reducing operating costs. In this study, the use of electric field contactors for the biodesulfurization of the model compound dibenzothiophene (DBT) as well as actual crude oil is investigated. The emulsion phase contactor (EPC) creates an emulsion of aqueous biocatalyst in the organic phase by concentrating forces at the liquid / liquid interface rather than imparting energy to the bulk solution as is done in impellerbased reactors. Characterization of emulsion quality and determination of rates of DBT oxidation to 2-hydroxybiphenyl (2-HBP) were performed for both batch stirred reactors (BSR) and the EPC. The EPC was capable of producing aqueous droplets of about $5 \mu \mathrm{m}$ in diameter using $3 \mathrm{~W} / \mathrm{L}$ whereas the impeller-based reactor formed droplets between 100 and $200 \mu \mathrm{m}$ with comparable power consumption. The presence of electric fields was not found to adversely affect biocatalytic activity. Despite the greater surface area for reaction afforded by the EPC, rates of DBT oxidation in both reactors were similar, demonstrating that the biocatalyst used (Rhodococcus sp. IGTS8) was not active enough to be mass transport limited. The EPC is expected to have tremendous impact upon reactor operating costs and biocatalyst utilization once advances biocatalyst development provide systems that are mass transport limited.

\footnotetext{
* Corresponding author, e-mail: ekn@ornl.gov

${ }^{\dagger}$ Research supported by the Office of Oil and Gas Processing and the Advanced Research and Technology Development Program of the Office of Fossil Energy, U.S. Department of Energy under contract DE-AC05-96OR22464 with Lockheed Martin Energy Research Corp. The submitted manuscript has been authored by a contractor of the U.S. Government under contract DE-AC0596OR22464. Accordingly, the U.S. Government retains a nonexclusive, royalty-free license to publish or reproduce the published form of this contribution, or allow others to do so, for U.S. Government purposes.
} 
Biological refining of fossil fuel feedstocks offers an attractive alternative to conventional thermochemical treatment due to the mild operating conditions and greater reaction specificity afforded by the nature of biocatalysis. Efforts in microbial screening and development have identified microorganisms capable of petroleum desulfurization (see for example (1-7)), denitrification (5), demetalization $(5)$, cracking $(5,8)$ and dewaxing. Further investigation and manipulation of enzymatic pathways responsible for these reactions (9) has led to processes which are approaching commercial application, particularly in the area of biological desulfurization $(6,10)$. Biological desulfurization of petroleum may occur either oxidatively (see for example $(2,4,11))$ or reductively $(1,12-14)$. In the oxidative approach, organic sulfur is converted to sulfate and may be removed in process water. This route is attractive due to the fact that it would not require further processing of the sulfur and may be amenable for use at the well head where process water may then be reinjected. In the reductive desulfurization scheme, organic sulfur is converted into hydrogen sulfide which may then be catalytically converted into elemental sulfur, an approach of utility at the refinery. Regardless of the mode of biodesulfurization, key factors affecting the economic viability of such processes are biocatalyst activity and cost, differential in product selling price, sale or disposal of co-products or wastes from the treatment process, and the capital and operating costs of unit operations in the treatment scheme.

While significant activity is progressing in the engineering and chemical modification of enzymes so that they may function in purely organic solutions (15, 16), inherent to all of the current bioprocessing of fossil feedstocks schemes is the need to contact a biocatalyst containing aqueous phase with an immiscible or partially miscible organic substrate. Traditionally, impeller-based stirred reactors are utilized for such mixing due to their ease of operation and wide acceptance in the chemical and biological processing industries. Such mechanically stirred reactors contact the aqueous and organic phases by imparting energy to the entire bulk solution, i.e. the impeller must move the contents of the reactor. Energy input in the stirred reactor is a function of the phase ratio, oil viscosity, density, reactor size, impeller speed, etc. (17). Typically, impeller based reactors are capable of achieving water or oil droplet sizes of $100-300 \mu \mathrm{m}$ in diameter and require on the order of 1-6 W/L to do so based upon empirical correlations (17). It is estimated that if impeller based systems were capable of producing $5 \mu \mathrm{m}$ droplets, it would require $\sim 25 \mathrm{~kW} / \mathrm{L}$ (18). Furthermore, no capacity exists for biocatalyst separation or emulsion breakage within the reactor. Alternative processing schemes (10) propose the use of "motionless mixers", in which the two phases are pumped over a reversing helical coil which creates turbulent eddies. While this method reduces the number of moving parts in the reactor, it does not reduce power requirements since costs are transferred from the impeller to the pumps required to move the liquids past the coil (19). 
Recent advances in the area of contactors for solvent extraction have lead to the development of electrically driven emulsion phase contactors (EPC) for efficient contact of immiscible phases (20-23). In this concept, the differing electrical conductivity between the aqueous and organic phases causes electrical forces to be focused at the liquid / liquid interface, creating tremendous shear force (see for example (24)). This shear causes the conductive phase to be dispersed (5 $\mu \mathrm{m}$ droplet size - (18)) into the non-conductive phase, but does so with decreased energy requirements relative to mechanical agitators due to the fact that energy is imparted only at the liquid / liquid interface and not the entire bulk solution (see (19) for a review). The configuration of the EPC developed at the Oak Ridge National employs two different types of electrode regions in order to increase liquid throughput. The first, termed the "nozzle region", provides a high capacity droplet dispersion by providing an electric field with a significant vertical component. This vertical field creates the dispersion at the nozzle entrance and accelerates it into the continuous phase. A second region termed the "operating channel" employs parallel plates carrying a modulated dc offset with high voltage spikes. This signal creates an oscillating horizontal electrical field which controls the residence time of the dispersed phase and serves to continuously coalesce and redisperse the droplets as they progress in a serpentine manner through the reactor. At the base of the reactor, an electrical field exists between the electrified central plate and the grounded aqueous phase, which accelerates the aqueous droplets to the organic / aqueous interface. In this manner, droplet coalescence and hence separation on the interface is enhanced.

With the success the EPC has exhibited in the area of solvent extraction, it was proposed that it could be an efficient reactor system for aqueous / oil contacting in biorefining (25). In this manuscript we assess the utility of the EPC for biodesulfurization reactions. The emulsion quality obtained in the EPC is compared to that obtained in bench scale stirred tank reactors and the rate of DBT oxidation in the two reactors is also juxtaposed. The effect of processing in the EPC on cell viability and activity is assessed, and it is demonstrated that the EPC is capable of processing crude oil as opposed to merely model organic systems.

\section{MATERIALS AND METHODS}

The oxidation of dibenzothiophene (DBT) in hexadecane was studied to investigate reactor design and performance in an easily tractable chemical system. Rhodococcus sp. wild strain IGTS8 (ATCC 53968) was provided by Energy BioSystems Corp. and served as the biocatalyst. Cells were supplied as a frozen paste and had a cell dry weight of $0.247 \mathrm{~g} / \mathrm{g}$ of original frozen material. The aqueous phase in all experiments consisted of $0.156 \mathrm{M}, \mathrm{pH} 7.5$ potassium phosphate buffer. DBT dissolved in n-hexadecane, served as the organic phase, with typical initial DBT concentrations being $0.6 \mathrm{wt} . \%$. 
Liquid samples collected from the reactors were centrifuged at 14,000 RPM for 5 minutes to separate the aqueous phase and cell debris. DBT and 2hydroxybiphenyl (2-HBP) concentrations in n-hexadecane were measured by gas chromatography using a Hewlett Packard 5890 gas chromatograph equipped with a flame ionization detector as described in (19). In the experiments reported here, DBT and 2-HBP concentrations in the aqueous phase were below our levels of detection. Hence only concentrations in the organic phase are reported.

Experiments conducted in batch stirred reactors (BSR) utilized $50 \mathrm{~g}$ of frozen Rhodococcus sp. wild type strain IGTS8 (ATCC 53968) cell paste which were brought up to $750 \mathrm{~mL}$ with $0.156 \mathrm{M} \mathrm{(pH} \mathrm{7.5)} \mathrm{phosphate} \mathrm{buffer} \mathrm{and} \mathrm{added} \mathrm{to} 250 \mathrm{~mL}$ of $0.6 \mathrm{wt} \% \mathrm{DBT}$ in $\mathrm{n}$-hexadecane. The reactor vessel was a 1-L VirTis OmniCulture fermenter, utilizing a 6-bladed Rushton-type impeller with 2 baffles. The impeller was mounted on the shaft 0.5 inches from the aerator and 2 inches from the bottom of the vessel. The reactor was kept at $30^{\circ} \mathrm{C}$, agitated at $800 \mathrm{RPM}$, and aerated with room air at a rate of 0.2 SLPM.

A schematic of EPC operation is shown in Figure 1. The Teflon body of the EPC measured $10 \mathrm{~cm} \times 10 \mathrm{~cm} \times 61 \mathrm{~cm}$. The front and rear plates of were made of clear Lexan, allowing for visual inspection of reactor operation. A thin sheet of Teflon was placed between the body and the front and rear plates to prevent wetting and current leakage to the Lexan. Three stainless steel electrodes, placed parallel to each other, measured $30 \mathrm{~cm} \times 6 \mathrm{~cm}$. The center electrode was charged, while the two outer electrodes were grounded. The center electrode was connected to the high-voltage electric through a supporting steel rod to avoid disturbance of electrostatic-spraying in the nozzle region. High-voltage (up to $40 \mathrm{kV}$ ) was generated using a pulsed DC power supply and automobile ignition parts. A power supply and two sweep/function generators were used to produce the signal which was then passed through an ignition coil to step up the signal. In order to prevent discharge of the electrodes through the circuit, a high-voltage diode was placed between the coil and the EPC. From the diode, the positively charged terminal was connected to the rings surrounding the capillary tubes, and the negative lead was attached to the center electrode. The charged rings created an initial dispersion of biocatalyst as the aqueous phase emerged from the capillary tubes. The parallel electrodes lower in the reactor enhanced droplet dispersion as the more dense aqueous phase descended to the bottom of the reactor.

In EPC experiments, the organic liquid served as the continuous phase into which an aqueous biocatalyst was dispersed. The organic phase consisted of $2,400 \mathrm{~mL}$ $\mathrm{n}$-hexadecane containing $0.6 \mathrm{wt} . \%$ dibenzothiophene. The temperature of the organic phase was controlled at $30^{\circ} \mathrm{C}$. Biocatalyst $(26.7 \mathrm{~g}$ of frozen cell paste brought to a volume of $100 \mathrm{~mL}$ with potassium phosphate buffer) was recirculated through the reactor at $5.0 \mathrm{~mL} / \mathrm{min}$ using a peristaltic pump. Aqueous phase containing the biocatalyst was sprayed into the reactor at the nozzle region, was continuously coalesced and redispersed in the operating region, and coalesced at the 
base of the EPC. To better aerate, sample, and control the aqueous phase, it was circulated from the reactor base to an external reservoir at a rate of $5.0 \mathrm{~mL} / \mathrm{min}$. The liquid was then returned to the top of the reactor through two $1.6-\mathrm{mm}-\mathrm{OD}, 1-\mathrm{mm}$ ID capillary tubes where it was again sprayed into the hexadecane. A water bath controlled the temperature of the jacketed aqueous reservoir at $30^{\circ} \mathrm{C}$. The $\mathrm{pH}$ was monitored throughout the experiment, and remained in the $\mathrm{pH}$ range of 7.0 to 7.5. In order to help alleviate possible oxygen deficiency inside the reactor, another diffuser was introduced $3 \mathrm{~cm}$ from the bottom of the EPC at airflow rate of 36 $\mathrm{mL} / \mathrm{min}$. Samples from the EPC were drawn hourly for twelve hours. Due to the small amount of 2-HBP production in the EPC, and hence greater associated error in $\mathrm{GC}$ analysis, samples were run in triplicate.

The average power consumption in the EPC was calculated as described in (19). The average power consumption was found to be $7.4 \mathrm{~W}$ which corresponds to approximately $3 \mathrm{~W} / \mathrm{L}$ and is in agreement with previously published values for the EPC $(18,22)$. This power is significantly smaller than that needed by mechanical agitation to produce the same size droplets (18).

Emulsion properties in the EPC and BSR were assessed by measuring the droplet size of the dispersed phase formed in each system. Drop size distribution in the batch stirred reactors was measured using a video technique as described in (19). Drop size distributions were measured using a 3:1 ratio of buffer to organic for three conditions: 1) $750 \mathrm{rpm}$, 2) $1000 \mathrm{rpm}$, and 3) $750 \mathrm{rpm}$ with $5 \mathrm{~g}$ of frozen biocatalyst added to the buffer. Note that under these conditions, diesel constituted the dispersed phase. Ex situ characterization of the EPC emulsion was conducted using a Coulter LS130 particle size analyzer. To ensure that the agitation of the sampling cell was not responsible for the emulsion measured, hexadecane $(15 \mathrm{~mL})$ and buffer $(200 \mu \mathrm{L})$ were placed in the cell with $20 \mu \mathrm{L}$ Triton X surfactant, and the size distribution of droplets was measured. The water / hexadecane emulsion from the EPC $(200 \mu \mathrm{L})$ was then placed in $15 \mathrm{~mL}$ of hexadecane with $20 \mu \mathrm{L}$ of Triton X and its size distribution was measured. Finally, to demonstrate that the instrument indeed was accurately reporting size distributions, a sample of $35 \mu \mathrm{m}$ garnet particles was assessed under identical conditions.

Since electric fields may be utilized in some applications for sterilization (26), it was desired to assess what, if any, effect the EPC has on biocatalyst viability and activity. Due to the difficulty in maintaining aseptic conditions in the EPC, plate counts of bacteria before and after operation in the EPC may be inaccurate. To directly address how the EPC may affect the activity of the biocatalyst, cells were first sprayed in the EPC, harvested by centrifugation, and then used as biocatalyst in batch stirred reactor desulfurization experiments. Resulting cell activity was compared to that of fresh cells which were never sprayed in the EPC. The EPC was operated as described above, except that rather than recirculating the biocatalyst through the EPC, $214 \mathrm{~g}$ of cells in $800 \mathrm{~mL}$ buffer were sprayed into the reactor at a 
rate of $10 \mathrm{~mL} / \mathrm{min}$ in a single pass. Cells were harvested through centrifugation (7,000 RPM, $30 \mathrm{~min})$. A sample of recovered biocatalyst was taken to determine the dry weight of the resulting cell paste. Forty grams of this paste were placed into a batch stirred reactor containing $700 \mathrm{~mL}$ of buffer and $250 \mathrm{~mL}$ of hexadecane with $0.6 \%$ DBT. A second batch stirred reactor in which no DBT was added to the hexadecane was used as a control to account for the residual DBT and HBP which may have been introduced with the biocatalyst.

The ability to effectively create an emulsion using the EPC is a function of the densities, viscosities, electrical conductivities, and interfacial surface tension of the two phases to be mixed. Since crude oil is more dense, viscous, and potentially more conductive than the model organic liquid hexadecane (hexadecane properties: density $0.78 \mathrm{~g} / \mathrm{mL}$, viscosity $4.2 \mathrm{cp}$, conductivity $3.0 \times 10^{-13} \mathrm{mho} / \mathrm{cm}$, interfacial surface tension with buffer 27 dynes $/ \mathrm{cm}$ at $21^{\circ} \mathrm{C}$ ), it is not known a priori whether the EPC is capable of creating a buffer / crude oil emulsion. In addition, due to the opaque nature of the crude oil, visual determination of EPC performance when using crude oil was not possible as it was in the hexadecane system. Crude oil was supplied by Dr. Robert G. Shong, (Texaco, Houston, TX). The oil had an API of 27 , a total sulfur content of $2 \%$ and a density, viscosity and electrical conductivity of $0.86 \mathrm{~g} / \mathrm{mL}, 42.2 \mathrm{cp}$ and $2.4 \times 10^{-10} \mathrm{mho} / \mathrm{cm}$ respectively, when measured at $21^{\circ} \mathrm{C}$. The interfacial surface tension of the oil with buffer was 12 dynes $/ \mathrm{cm}$ at $22^{\circ} \mathrm{C}$. In order to visually assess the ability of the EPC to form an emulsion using an organic of similar density and viscosity as the crude oil, mineral oil was used as a model organic liquid. At $20^{\circ} \mathrm{C}$, the mineral oil exhibited a viscosity of $235 \mathrm{cp}$, and buffer could not be successfully sprayed into the oil in the EPC due to the fact that the aqueous phase built up at the nozzle region since it did not easily fall through the viscous oil. When heated to $41^{\circ} \mathrm{C}$, the mineral oil exhibited a density of $0.86 \mathrm{~g} / \mathrm{L}$, and a viscosity of $50 \mathrm{cp}$. At this lower viscosity (still higher than the viscosity of the crude oil) successful emulsion formation was observed in the EPC. Thus, the ability to successfully spray the buffer solution in mineral oil served as a strong indicator of the ability to also spray the buffer solution into crude oil. In EPC experiments utilizing crude oil, the crude replaced hexadecane as the organic phase. All other experimental conditions remained the same as the hexadecane experiments with the exception of a water-cooled condenser added at the reactor apex to return volatilized organic species to the reactor.

\section{RESULTS AND DISCUSSION}

Diesel drop sizes which were observed in a BSR were 1) $210 \pm 108 \mu \mathrm{m}, \mathrm{n}=305$ for $750 \mathrm{rpm}$ with no cells, 2) $188 \pm 96 \mu \mathrm{m}, \mathrm{n}=309$ for $1000 \mathrm{rpm}$ with no cells , and 3) $118 \pm 47 \mu \mathrm{m}, \mathrm{n}=323$ for $750 \mathrm{rpm}$ with $5 \mathrm{~g}$ of frozen biocatalyst added to the buffer. As expected, at higher agitation, the drop size does decrease. Furthermore, at a given agitation speed, the addition of cells decreases the droplet size significantly, indicating the presence of a surfactant agent in the biocatalyst. Drop sizes produced by agitation in the BSR were typically between 100 and $200 \mu \mathrm{m}$ in diameter. 
The results of EPC emulsion characterization are shown in Figure 2. An appreciable volume of the emulsion from the EPC consisted of droplets between 1 and $10 \mu \mathrm{m}$ in diameter. However, most of this sample consisted of droplets between 30 and $100 \mu \mathrm{m}$. It is unknown whether these large droplets resulted from aqueous coalescence during sampling and analysis or if they truly represent the size distribution present in the EPC. This size distribution is thus a "worst case scenario" in that due to coalescence during the collection and sizing procedure, the actual size distribution within the reactor can said to be at least this fine. The size distribution shown for a water and hexadecane mixture agitated only by the Micro Volume Module demonstrated that the $1-10 \mu \mathrm{m}$ emulsion seen in the EPC sample was not the result of mixing taking place in the sizing instrument since this mixing was only able to form $100-1,000 \mu \mathrm{m}$ sized droplets in a water hexadecane mixture in which surfactant was also present. In addition, the size distribution shown for the $35 \mu \mathrm{m}$ garnet particles in hexadecane demonstrates the accuracy of the instrument and the fact that the $1-10 \mu \mathrm{m}$ droplets reported in the EPC were not the result of debris in the hexadecane.

The ability to form fine emulsions in the EPC without increasing energy utilization could have tremendous impact upon processing costs assuming that the biocatalyst utilized is active enough to be mass transport limited (i.e. the biocatalyst is so active that the rate limiting step in desulfurization is the mass transport of the sulfur bearing compound to the cell surface and not the length of time needed for reaction once the cell is in contact with the sulfur moiety). For instance, on a 1-L basis, a BSR using a 3:1 water to oil ratio and producing oil droplets of $150 \mu \mathrm{m}$ in diameter creates $1 \times 10^{5} \mathrm{~cm}^{2}$ of interfacial surface area. On the same volume basis, an EPC creating $5 \mu \mathrm{m}$ diameter aqueous droplets and having a $5 \%$ aqueous hold-up creates $6 \times 10^{5} \mathrm{~cm}^{2}$ of interfacial surface area, but requires $1 / 15^{\text {th }}$ the aqueous volume to do so. In a mass transport limited system, the rate of desulfurization would thus be expected to be 6 times as large while using $93 \%$ less biocatalyst.

The rates of 2-HBP production from DBT in an EPC run and three separate BSR runs are shown in Figure 3. Rates of 2-HBP production were within experimental variance and no appreciable difference in desulfurization rates were seen between the reactors when reported on a mg 2-HBP per gram biomass basis. Of course since the EPC treated $2.4 \mathrm{~L}$ of $0.6 \mathrm{wt} \% \mathrm{DBT}$ with $26.7 \mathrm{~g}$ of biocatalyst whereas the BSR runs treated $250 \mathrm{~mL}$ of $0.6 \mathrm{wt} \% \mathrm{DBT}$ with $50 \mathrm{~g}$ of biocatalyst, the change in concentration of 2-HBP in the EPC reactor was much smaller than that seen in the BSR. This small change in concentration over the reactor run accounts for the large standard deviation in the data points reported for the EPC. Desulfurization activity of the Rhodococcus sp. in both reactors was typically between 1 and $5 \mathrm{mg} 2-\mathrm{HBP}$ produced per dry gram of biocatalyst per hour. Note that in the experiments reported here, the only available carbon and energy source for the biocatalyst other than what may be carried over in the frozen cell paste, was hexadecane and DBT. 
Other studies have utilized additional external carbon and energy sources and have reported higher activities with Rhodococcus sp. The rates of 2-HBP production from DBT by Rhodococcus sp. which had been previously sprayed in the EPC and then placed into a BSR are shown in Figure 3. The rate of 2-HBP production by these cells lies within the experimental variability seen with fresh biocatalyst. The slightly diminished activity may be attributable to loss of the initial nutrients present in the cell paste due to extraction into the hexadecane during the electrospraying process. This initial assessment of the effect of EPC operation on cell viability and activity indicates no appreciable effect on desulfurization activity by Rhodococcus sp.

Aqueous phase containing biocatalyst was successfully sprayed into crude oil at $30^{\circ} \mathrm{C}$ using the EPC. While the emulsion could not be confirmed visually, the electrical waveforms observed form the EPC were similar to those observed during operation with hexadecane as the organic phase. While initial results have shown no measurable change in the oil's total sulfur content upon treatment in the EPC, this is not surprising due to the low catalytic ability and large volume of oil being treated. For instance, assuming a biocatalytic activity of $3 \mathrm{mg} 2-\mathrm{HBP} / \mathrm{dry}$ gm biocatalyst per hour, one would expect the $2.4 \mathrm{~L}$ of crude oil's sulfur content to be reduced only from 2.000 to 1.998 after 6 hours of treatment with 26 grams of cells.

The emulsion phase contactor has been demonstrated to be an effective instrument for the creation of fine water / oil emulsions for crude oil bioprocessing. Tremendous surface area for reaction is formed in the EPC with no increase in energy consumption compared to batch stirred reactors. While the high electric fields utilized by the EPC have been demonstrated to be fully compatible with biological processing, we have been unable to demonstrate an increase in desulfurization rate in the EPC relative to batch stirred reactors due to the low activities of the biocatalyst used in these experiments. Since the current biocatalyst is not active enough to be mass transport limited, the increased surface area afforded by the EPC did not increase the observed rate of desulfurization. Despite this, the EPC is expected to be a valuable tool in the bioprocessing of oil as developments in biocatalyst performance provide commercially viable strains which are mass transport limited in batch stirred systems.

\section{ACKNOWLEDGMENTS}

This work was supported by the Office of Oil \& Gas Processing, U.S. Department of Energy under contract DE-AC05-96OR22464 with Lockheed Martin Energy Research Corp. The authors acknowledge the material contributions of Energy BioSystems Corp. and Texaco.

\section{REFERENCES}

1. Finnerty, W.R.(1993),Fuel. 72,1631-1634.

2. Kayser, K.J., B.A. Bielaga-Jones, K. Jackowski, O. Odusan, and J.J. Kilbane.(1993),Journal of General Microbiology. 139,3123-3129. 
3. Kim, T.S., H.Y. Kim, and B.H. Kim.(1990),Biotechnology Letters. 12,757-760.

4. Lee, M.K., S. J.D., and M.J. Grossman.(1995),Applied and Environmental Microbiology. 61,4362-4366.

5. Lin, M.S., E.T. Premuzic, J.H. Yablon, and W.M. Zhou.(1996),Applied Biochemistry and Biotechnology. 57/58,659-664.

6. Monticello, D.J.(1994),Hydrocarbon Processing. February 1994,39-45.

7. Ohshiro, T., Y. Hine, and Y. Izumi.(1994),FEMS Microbiology Letters. 118,341-344.

8. Premuzic, E.T., M.S. Lin, J.Z. Jin, B. Manowitz, and L. Racaniello, Biochemical Alteration of Crude Oils in Microbial Enhanced Oil Recovery, in Biohydrometallurgical Technologies, A.E. Torma, M.L. Apel, andC.L. Briarley, Editor. 1993, The Minerals, Metals, and Materials Society: p. 401-413.

9. Denome, S.A., C. Oldfield, L.J. Nash, and K.D. Young.(1994),Journal of Bacteriology. $176,6707-6716$.

10. Dounias, G.A. and K.D. Stavropoulos, Economic Feasibility of Biochemically Upgrading Heavy Crudes. (1995), Brookhaven National Laboratory:

11. Kilbane, J.J. and B.A. Bielaga.(1990),CHEMTECH. december,747-751.

12. Kim, H.Y., T.S. Kim, and B.H. Kim.(1990),Biotechnology Letters. 12,761-764.

13. Lizama, H.M., L.A. Wilkins, and T.C. Scott.(1995),Biotechnology Letters. 17,113-116.

14. Kim, B.H., H.Y. Kim, T.S. Kim, and D.H. Park.(1995),Fuel Processing Technology. 43,87-94.

15. Almarsson, O. and A.M. Klibanov.(1996),Biotechnology and Bioengineering. 49,87-92.

16. Woodward, C.A. and E.N. Kaufman.(1996),Biochemistry and Biotechnology. in press.

17. Perry, R.H., D.W. Green, and J.O. Maloney, ed. Perry's Chemical Engineering Handbook. 6 ed.

1984, McGraw-Hill: New York. 2336.

18. Scott, T.C. and W.G. Sisson.(1988),Separation Science and Technology. 23,1541-1550.

19. Kaufman, E.N., J.B. Harkins, M. Rodriguez, P.T. Selvaraj, C. Tsouris, and S.E. Murphy

(1996), Fuel Processing Technology. Submitted for Publication.

20. Kowalski, W. and Z. Ziolkowski.(1981),Int. Chem. Eng. 21,323.

21. Martin, L., P. Vignet, C. Fombarlet, and F. Lancelot.(1983),Sep. Sci. Technol. 18,1455.

22. Scott, T.C., D.W. DePaoli, and W.G. Sisson.(1994),Ind. Eng. Chem. Res. 33,1237-1244.

23. Thorton, J.D.(1968), Rev. Pure and Appl. Chem. 18,197.

24. Ptasinski, K.J. and P.J. Kerkhof.(1992),Sep. Sci. Technol. $27,995$.

25. Lizama, H.M., T.C. Scott, and C.D. Scott, Apparatus and Method for the Desulfurization of

Petroleum by Bacteria. (1995), United States Patent Number 5,458,752:

26. Grahl, T. and H. Markl.(1996),Appl. Microbiol. Biotechnol. 45,148-157.

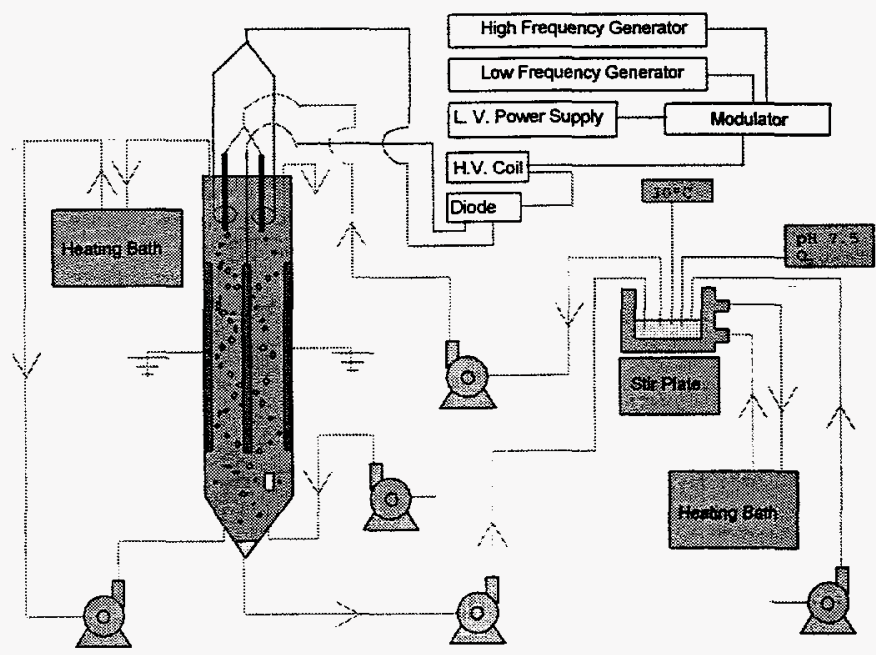

Figure 1: Schematic of the emulsion phase contactor and ancillary equipment. 


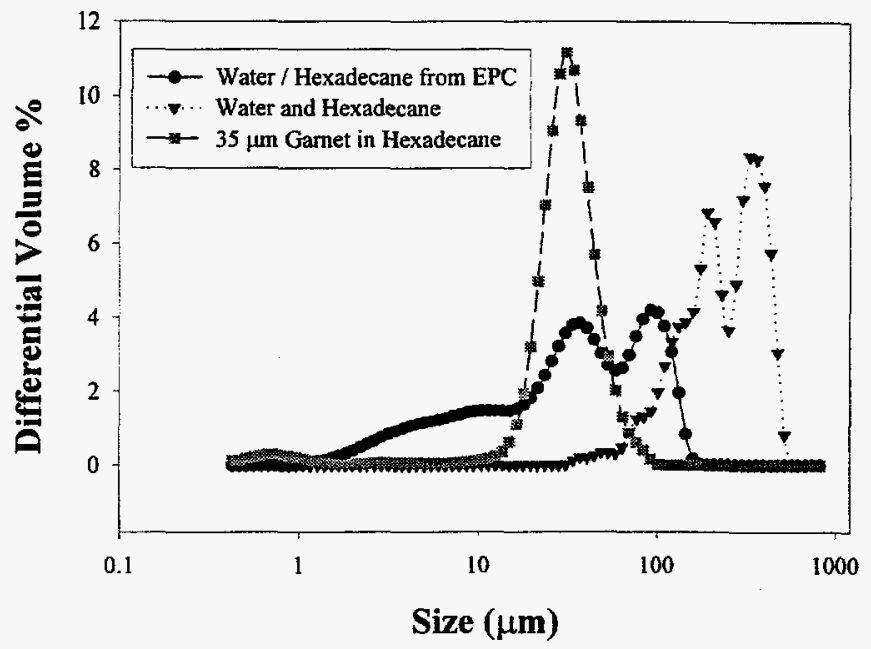

Figure 2: Characterizing the EPC emulsion using laser light scattering. The emulsion from the EPC revealed a peak owing to droplets in the $1-10 \mu \mathrm{m}$ size range as well as peaks $<100 \mathrm{~mm}$ presumably due to coalescence during sampling. A mixture of hexadecane and water placed in the sampling cell exhibited droplets $>100 \mu \mathrm{m}$ in diameter, demonstrating that the sampling procedure itself was not responsible for the emulsion measured form the EPC. Finally, the size distribution for $35 \mu \mathrm{m}$ garnet particle in hexadecane demonstrate the accuracy of the measurements and also demonstrate the small droplets seen in the EPC emulsion were not due to debris in the hexadecane used. Mean droplet sizes were $49 \pm 40,267 \pm 121$ and $34 \pm 12 \mu \mathrm{m}$ for the EPC emulsion, hexadecane and water and garnet particles respectively.

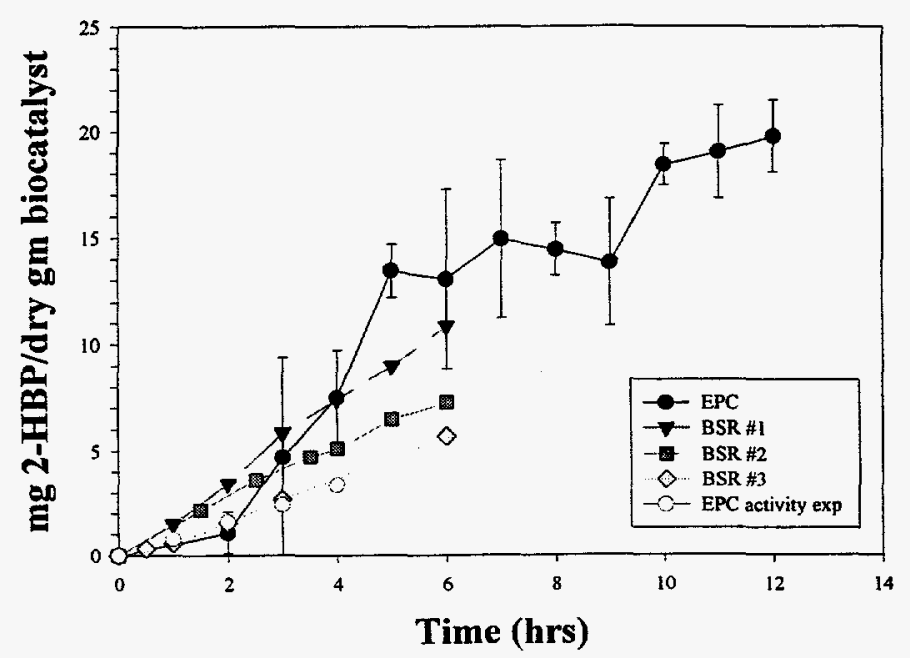

Figure 3: Rates of HBP production from DBT in the EPC, batch stirred reactors and by cells that were sprayed in the EPC and then placed into a batch stirred reactor. Rates were found to be identical within experimental variability. From these experiments it can be concluded that the EPC has no detrimental effect on cell activity and that the biocatalyst utilized is not active enough to be mass transport limited for it does not benefit from the increased surface area for reaction afforded by the EPC. 